\title{
Isolamento de coliformes, estafilococos e enterococos de leite cru provenientes de tanques de refrigeração por expansão comunitários: identificação, ação lipolítica e proteolítica
}

\author{
Isolation of coliforms, staphylococci, and enterococci in raw milk from communitarian \\ expansion refrigeration tanks: identification, lipolytic and proteolytic action
}

\author{
Victor Maximiliano Reis TEBALDI ${ }^{1}$, Thales Leandro Coutinho de OLIVEIRA ${ }^{1}$, \\ Cleube Andrade BOARI ${ }^{1}$, Roberta Hilsdorf PICCOLI ${ }^{1 \star}$
}

\begin{abstract}
Resumo
O isolamento e a identificação de microrganismos em leite cru se tornam interessantes do ponto de vista de saúde pública, pois dependendo das espécies isoladas, ações direcionadas podem ser tomadas visando a melhoria de sua qualidade. A deterioração do leite é conseqüência sobretudo do crescimento de microrganismos psicrotróficos, que produzem lipases e proteases termoestáveis que não são desnaturadas durante o processo de pasteurização, conferindo sabores e odores rançoso e amargo, respectivamente. Assim, o objetivo deste trabalho foi isolar e identificar os principais gêneros de bactérias pertencentes à família Enterobacteriaceae, Gram-negativas oxidase positiva, gêneros Staphylococcus e Enterococcus, bem como atividade de lipases e proteases de 16 propriedades rurais do município de Boa Esperança-MG. As bactérias Gram-negativas foram isoladas em ágar eosina azul de metileno (EMB) e ágar Entérico Hektoen. Estafilococos foram isolados em ágar Baird-Parker e Enterococcus em ágar KF. Colônias de interesse foram coletadas e submetidas à coloração de Gram, e às provas de catalase e oxidase. Após esses procedimentos, os isolados selecionados foram identificados utilizando-se Bactray I, II e III; Api 20 Strep; e provas sugeridas pelo Bergey’s Manual of Determinative Bacteriology. A identificação sorológica de Enterococcus foi realizada utilizando-se Prolex. O leite oriundo das 16 propriedades continha cepas de microrganismos fecais como Escherichia coli e Enterococcus do grupo D de Lancefield. Bactérias Gram-negativas oxidase positiva foram identificadas em cinco propriedades. Staphylococcus foram encontrados em 10 propriedades. O leite coletado nas fazendas investigadas possui microrganismos que comprometem sua qualidade. Todos os grupos de microrganismos testados revelaram atividades de lipase e protease.
\end{abstract}

Palavras-chave: leite cru; identificação bacteriana; bactérias mesofílicas; lípases; proteases.

\begin{abstract}
Isolation and identification of microorganisms in raw milk is interesting from the viewpoint of public health, since, depending on the species isolated, directed actions may be taken to improve milk quality. Milk deterioration is mainly the result of the growth of psychrotrophic microorganisms that produce heat-resistant lipases and proteases which are not denatured during pasteurization, conferring rancid and sour flavors, respectively. Thus, this work aimed at isolating and identifying the main genera of bacteria belonging to the Enterobacteriaceae family, oxidase-positive Gram-negative, Staphylococcus and Enterococcus genera, as well as determining lipase and protease activity in 16 rural farms in Boa Esperança-MG, Brazil. The Gram-negative bacteria were isolated in Eosin Methylene Blue (EMB) and Hektoen Enteric agar media. Staphylococci were isolated in Baird-Parker agar and Enterococcus in KF agar. Colonies of interest were collected and submitted to Gram stain and to catalase and oxidase tests. Following these procedures, the isolates selected were identified using Bactray I, II and III; Api 20 Strep and tests suggested by Bergey's Manual of Determinative Bacteriology. Sorological identification of Enterococcus was carried out using Prolex. Milk from the 16 rural properties contained strains of fecal microorganisms, such as Escherichia coli and Enterococcus from the Lancefield D group. Oxidase-positive Gram-negative bacteria were identified in five farms. Staphylococcus was found in 10 farms. Milk collected from the farms investigated contained microorganisms that compromise its quality. All the microorganism groups tested showed lipase and protease activities.
\end{abstract}

Keywords: raw milk; bacterial identification; mesophyllic bacteria; lipases; proteases.

\section{Introdução}

A natureza complexa e interligada para se obter alimentos e produzi-los de forma segura tem sido amplamente reconhecida. A aproximação integrada para controlar a segurança dos alimentos por toda a cadeia produtiva tem se tornado importante aspecto para se garantir grande número de alimentos seguros. Pensando em segurança, vários países elaboraram e introdu- ziram regulamentações para garantir a segurança do alimento em diferentes estágios na cadeia de produção (VALEEVA et al., 2005). Assim, no Brasil, em 2005, entrou em vigor a Instrução Normativa 51 na qual, dentre vários fatores a serem adotados para a obtenção de leite de boa qualidade e seguro, implementou-se a coleta do leite a granel e seu resfriamento a $4{ }^{\circ} \mathrm{C} \mathrm{em}$ 
tanques de resfriamento por expansão, até que esse possa chegar às indústrias (BRASIL, 2002). O principal objetivo dessas regulamentações é limitar o desenvolvimento da microbiota mesofílica em que se encontra a grande maioria dos microrganismos patógenos e deterioradores, sendo essa microbiota usada por muitos pesquisadores para diagnosticar múltiplos problemas, correntes ou em potencial, que possam existir nos rebanhos leiteiros (JAYARAO et al., 2004). A concentração de bactérias aeróbias mesófilas encontrada no leite cru em tanques de refrigeração

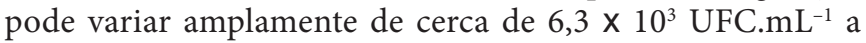
valores superiores a $10^{5}$ UFC. $\mathrm{mL}^{-1}$ (BOOR et al., 1998; HAYES et al., 2001). Entretanto, no leite, não são encontradas apenas bactérias mesofílicas. A microbiota predominante no leite cru geralmente inclui espécies de bactérias do ácido láctico (Lactococcus, Lactobacillus spp., Leuconostoc, Enterococcus ou Streptococcus spp.), Pseudomonas spp., bactérias pertencentes à família Micrococcaceae (Micrococcus e Staphylococcus spp.) e leveduras. Outros grupos microbianos presentes no leite cru incluem Bacillus, Clostridium, Listeria spp. e enterobactérias. Há também muitas espécies como Acinetobacter, Alcaligenes, Flavobacterium e Aeromonas, Arthrobacter, Corynebacterium, Brevibacterium e Propionibacterium (LAFARGE et al., 2004). Muitos desses microrganismos que compõem a microbiota do leite são psicrotróficos, que, sob baixas temperaturas impostas pelo armazenamento em tanque de expansão, conseguem se multiplicar e produzir enzimas, proteases e lipases, capazes de deteriorar o leite sob refrigeração; assim, a vida de prateleira do leite cru resfriado não consegue exceder cinco dias.

Embora a legislação coloque que a temperatura do leite mantido em tanque de refrigeração por expansão deva ser mantida a $4^{\circ} \mathrm{C}$, a realidade, em Boa Esperança-MG, e em seu entorno é outra. Levantamentos da temperatura do leite mantido em tanques de refrigeração dessa região mostraram que a temperatura do leite pode alcançar até $14^{\circ} \mathrm{C}$ (comunicação pessoal). A essa temperatura, microrganismos mesofílicos têm a capacidade de se multiplicar produzindo também enzimas extracelulares como lipases e proteases que contribuem para a deterioração do leite. Outro fator observado nesse levantamento é que o leite, muitas vezes, permanece mais do que 24 horas dentro do tanque sob temperatura inadequada, sendo esse um fator a mais para contribuir com a alteração do número da microbiota mesofílica (comunicação pessoal).

Devido às condições higiênico-sanitárias e a alterações físico-químicas e químicas que ocorrem no leite armazenado em tanque de resfriamento na região de Boa Esperança, objetivou-se detectar microrganismos indicadores de qualidade, bem como suas atividades lipolítica e proteolítica, as quais são de suma importância na deterioração do produto.

\section{Material e métodos}

\subsection{Obtenção das amostras de leite}

Devido ao grande número de tanques de refrigeração comunitários com problemas em qualidade localizados no município de Boa Esperança-MG, foram analisadas 16 amostras de leite cru, provenientes de 16 tanques de refrigeração por expansão, todos localizados em diferentes comunidades desse município. As amostras, denominadas de CXM; AM; MP; SB; PLT; CC; FER; BV; EST; FLC; AV; CV; CCMP; SDN; EV; e SAP, foram coletadas em tanques comunitários e conduzidas ao Laboratório de Microbiologia de Alimentos da Universidade Federal de Lavras para realização de análises microbiológicas. As referidas amostras foram coletadas durante quatro semanas, sendo realizadas análises de quatro amostras por semana.

\subsection{Preparo das amostras}

As amostras tiveram seus frascos, ainda fechados, agitados aproximadamente 20 vezes para sua homogeneização. Após a homogeneização, alíquotas de $1 \mathrm{~mL}$ foram transferidas para tubos de ensaio contendo $9 \mathrm{~mL}$ de água peptonada estéril a $0,1 \%(\mathrm{p} / \mathrm{v})$, sendo realizadas diluições seriadas.

\subsection{Análises microbiológicas}

Todas as análises microbiológicas foram realizadas de acordo com ICMSF (2000).

\section{Determinação de coliformes totais, termotolerantes e enterobactérias}

Foi utilizada a Técnica do Número Mais Provável empregando-se séries de 3 tubos. Alíquotas de $1 \mathrm{~mL}$ foram transferidas para tubos contendo Lauril Sulfato Triptose (LST) e incubados a 35 ${ }^{\circ} \mathrm{C} / 24-48$ horas. Foram considerados tubos positivos aqueles que apresentavam turvação e produção de gás. Alíquotas dos tubos positivos foram transferidas para tubos contendo caldo Bile Verde Brilhante e incubadas a $35^{\circ} \mathrm{C} / 24-48$ horas, e para tubos contendo caldo Escherichia coli (EC) e incubadas a $45^{\circ} \mathrm{C} / 24-48$ horas em banho-maria para confirmação de coliformes termotolerantes. A partir dos tubos de caldo Escherichia coli (EC) positivos, alíquotas foram estriadas em ágar Eosina Azul de Metileno (EMB) e ágar Entérico (Hektoen). Colônias com diferentes morfotipos foram coletadas e transferidas para tubos contendo caldo Brain Heart Infusion (BHI) e incubados a $37{ }^{\circ} \mathrm{C} / 24-48$ horas. Após esse período e novo cultivo em ágar TSA por $37^{\circ} \mathrm{C} / 24-48$ horas, alíquotas foram transferidas para tubos contendo ágar Simples Fosfatado. Estes foram incubados a $37^{\circ} \mathrm{C} / 24-48$ horas e mantidos à temperatura ambiente para posterior identificação. Esta foi realizada empregando-se kits de identificação Bactray I e II ${ }^{\circledast}$ para microrganismos Gram-negativos oxidase negativa e Bactray III ${ }^{\oplus}$ para os microrganismos Gram-negativos oxidase positivas.

\section{Determinação de estafilococos coagulase positiva e espécies de Staphylococcus}

O número de estafilococos coagulase positiva foi determinado utilizando-se ágar Baird-Parker ( $37^{\circ} \mathrm{C} / 48$ horas). $\mathrm{O}$ número da raiz quadrada do número de colônias típicas e atípicas formadas nas placas foi utilizado para a coleta de colônias que foram transferidas para caldo Brain Heart Infusion (BHI), sendo incubadas a $37^{\circ} \mathrm{C} / 24-48$ horas. A cultura foi purificada empregando-se ágar TSA $\left(37^{\circ} \mathrm{C} / 24-48\right.$ horas) e transferida para ágar Simples Fosfatado $\left(37^{\circ} \mathrm{C} / 24-48\right.$ horas). Após esta etapa, os isolados foram mantidos em temperatura ambiente para posterior identificação por meio de coloração de Gram, oxidase, 
catalase, coagulase em plasma de coelho-EDTA, termonuclease (DNAse) e testes bioquímicos complementares (BERGEY'S MANUAL OF DETERMINATIVE BACTERIOLOGY, 1994).

\section{Determinação de Enterococcus}

A contagem total de Enterococcus foi determinada utilizandose ágar $\mathrm{KF}\left(37^{\circ} \mathrm{C} / 48\right.$ horas). Colônias características foram transferidas para caldo $\mathrm{BHI}$ e incubadas a $37^{\circ} \mathrm{C} / 24-48$ horas. Alíquotas da cultura foram transferidas para ágar TSA $\left(37^{\circ} \mathrm{C} / 24-48\right.$ horas $)$, visando isolamento e purificação, e mantidas em ágar Simples Fosfatado com prévio crescimento a $37{ }^{\circ} \mathrm{C} / 24-48$ horas, para posterior identificação bioquímica das espécies. Testes de catalase e oxidase e coloração de Gram foram realizados. A identificação foi realizada utilizando-se API 20 Strep ${ }^{*}$. Após a identificação, os isolados foram sorotipados utilizando-se o kit Prolex ${ }^{\circ}$.

\subsection{Atividade de lipase e protease}

Todas as cepas isoladas nas análises anteriores foram submetidas à capacidade de produção de lipase utilizando-se o ágar Tributirina suplementado com púrpura de bromocresol a 1\% (v/v) para os microrganismos Gram-positivos e suplementado com azul de ortotoluidina a $1 \%(\mathrm{v} / \mathrm{v})$ para os microrganismos Gram-negativos. Após a semeadura, os meios foram incubados a $28^{\circ} \mathrm{C}$ por cinco dias. A atividade proteolítica dos isolados foi avaliada empregando o Milk Ágar suplementado com solução de leite em pó desnatado a $10 \%(\mathrm{v} / \mathrm{v})$, com posterior incubação dos meios a $28^{\circ} \mathrm{C} / 24-48$ horas.

Nos dois ensaios realizados, a interpretação dos testes positivos pôde ser verificada por meio de formação de halos transparentes ao redor das colônias formadas.

\section{Resultados e discussão}

Na Tabela 1, estão expostos os resultados da quantificação de coliformes totais, termotolerantes, estafilococos coagulase positiva e Enterococcus sp. obtidos das 16 amostras de leite provenientes dos tanques de expansão.

Das 16 amostras analisadas, $31,25 \%$ apresentaram contagem de coliformes termotolerantes acima de $10^{3} \mathrm{NMP} . \mathrm{mL}^{-1}$, valor considerado por Murphy (1997), citado por Badaró (2007), como indicativo de higiene deficitária na obtenção do leite. Contudo, nos tanques restantes, a concentração desses microrganismos pode ser considerada baixa. Esses números refletem a preocupação dos produtores em obter leite de boa qualidade uma vez que políticas de pagamento por qualidade do leite têm sido empregadas em vários laticínios e cooperativas no Brasil. Coliformes termotolerantes, tais como E.coli não patogênica prevalece no trato digestivo do gado (DIEZ-GONZALEZ et al., 1998; VAN KESSEL et al., 2002; LAVEN et al., 2003), e assumese que há uma correlação entre sua presença com organismos patógenos, sendo, freqüentemente, usados como indicadores de contaminação fecal e de potencial risco da presença de patógenos zoonóticos. Coliformes termotolerantes, como E. coli, podem alcançar os tanques de refrigeração tanto via secreção intramamária como via contaminação fecal do úbere ou equipamentos utilizados na ordenha. Van Kessel et al. (2002), em estudo sobre a prevalência de Salmonella, Listeria e coliformes termotolerantes em tanque de refrigeração, encontraram que apenas 7\% das 861 amostras de leite coletadas não se encontravam contaminadas com coliformes termotolerantes. No presente estudo, foi encontrado que 6,25\% das amostras não apresentavam coliformes termotolerantes, resultado semelhante ao encontrado pelos autores. Estes autores, como encontrado neste estudo, também obtiveram grande variação nas concentrações de coliformes termotolerantes no leite proveniente de tanques de expansão.

Embora procedimentos de higiene sejam utilizados por muitos produtores para obtenção de leite com baixa contaminação fecal, a presença de estafilococos coagulase positiva em elevadas concentrações encontrada neste estudo podem refletir problemas de sanidade do rebanho, como a presença de

Tabela 1. Número de coliformes totais e termotolerantes, estafilococos coagulase positiva e Enterococcus sp. encontrados nas 16 amostras de leite provenientes dos 16 tanques de expansão comunitários de Boa Esperança - MG.

\begin{tabular}{lccrr}
\hline Propriedades & Coliformes a $35^{\circ} \mathrm{C}$ & Coliformes a $44,5^{\circ} \mathrm{C}$ & Estafilococos Coagulase positiva & Enterococcus sp. \\
\hline (Amostras) & NMP.mL & UFC.mL ${ }^{-1}$ & $\mathrm{UFC.mL}^{-1}$ \\
\hline CXM & 9 & NMP.mL & $1,78 \times 10^{6}$ & $2,86 \times 10^{5}$ \\
AM & $1,1 \times 10^{3}$ & - & $7,23 \times 10^{6}$ & $1,54 \times 10^{6}$ \\
MP & $1,1 \times 10^{4}$ & $2,4 \times 10^{2}$ & $4,22 \times 10^{6}$ & $2 \times 10^{6}$ \\
SB & $4,610^{2}$ & 43 & $4,36 \times 10^{6}$ & $1,78 \times 10^{6}$ \\
PLT & $1,1 \times 10^{5}$ & $4,6 \times 10^{2}$ & $1,73 \times 10^{7}$ & $2,58 \times 10^{6}$ \\
CC & 93 & $1,1 \times 10^{5}$ & $2,4 \times 10^{5}$ & $2,5 \times 10^{4}$ \\
FER & 43 & 43 & $2,4 \times 10^{3}$ & $5,3 \times 10^{3}$ \\
BV & $\leq 2400$ & 43 & $2,3 \times 10^{4}$ & $2,2 \times 10^{6}$ \\
EST & $1,5 \times 10^{4}$ & $1,1 \times 10^{3}$ & $5,2 \times 10^{4}$ & $2,5 \times 10^{5}$ \\
FLC & 93 & - & $1,4 \times 10^{5}$ & $1,1 \times 10^{4}$ \\
AV & $4,6 \times 10^{2}$ & 4 & $6,4 \times 10^{4}$ & $4 \times 10^{3}$ \\
CV & $4,6 \times 10^{3}$ & $7,5 \times 10^{2}$ & $1,7 \times 10^{4}$ & $8,2 \times 10^{5}$ \\
CCMP & $2,4 \times 10^{2}$ & 43 & $2,4 \times 10^{5}$ & $5,3 \times 10^{4}$ \\
SDN & $1,1 \times 10^{4}$ & $4,6 \times 10^{3}$ & $2,7 \times 10^{4}$ & $1,5 \times 10^{4}$ \\
EV & $\leq 2400$ & $\leq 2400$ & $2,7 \times 10^{4}$ & $1,4 \times 10^{7}$ \\
SAP & $\leq 2400$ & $\leq 2400$ & $2,7 \times 10^{4}$ & $1,15 \times 10^{5}$ \\
\hline
\end{tabular}


mastite subclínica, não sendo esses esforços tão efetivos para a eliminação desse microrganismo. Além de refletir as condições sanitárias do rebanho, elevados números de estafilococos coagulase positiva, maiores que $10^{5} \mathrm{UFC} . \mathrm{mL}^{-1}$, aumentam o risco de produção de toxinas estafilocócicas que são resistentes ao processo de pasteurização. Como o leite é mantido por cerca de 24 horas dentro do tanque de refrigeração a temperaturas superiores a $4{ }^{\circ} \mathrm{C}$, esse fato é passível de ocorrer. A produção de enterotoxina se dá em temperatura ótima de $40-45^{\circ} \mathrm{C}$, no entanto tem-se detectado a produção das toxinas entre 10 e $46^{\circ} \mathrm{C}$ (TATINI, 1973).

A contaminação bacteriana pode ser originada de fontes múltiplas, tais como, vacas com mastite, sujidades presentes no úbere e limpeza inadequada dos equipamentos de ordenha. A presença de Enterococcus sp. indica problemas nas condições higiênico-sanitárias de obtenção de leite. Além disso, sabe-se que o consumo de leite contaminado por esses microrganismos está relacionado com a febre escarlatina e a dor de garganta séptica.

\subsection{Identificação dos microrganismos Gram-negativos}

\section{Colônias isoladas a partir do EC}

Conforme resultados expressos na Tabela 2, grande diversidade de representantes da família Enterobacteriaceae foi isolada, bem como bactérias Gram-negativas oxidase positivas, representantes dos gêneros, Burkholderia, Alcaligenes e Pseudomonas.

Microrganismos patógenos como Escherichia coli, Yersinia enterocolitica, Yersinia pseudotuberculosis, Klebsiella pneumoniae revelaram-se presentes na maioria das propriedades investigadas. Bactérias do gênero Enterobacter podem conferir ao leite odor semelhante ao de estábulo (FRANCO; LANDGRAF, 2003). A Yersinia enterocolitica está presente em todo o ambiente (FORSYTHE, 2002). Em algumas das propriedades investigadas verificou-se a presença de pequenas criações de porcos, havendo a possibilidade desses microrganismos presentes nos chiqueiros contaminarem o solo e o lençol freático, contaminando assim a água dos poços utilizada nessas propriedades, sendo essa a causa da presença desse microrganismo no leite.

A maioria dos microrganismos contaminantes do leite inclui patógenos humanos que são membros da família Enterobacteriaceae. As doenças diarréicas mais freqüentemente diagnosticadas são causadas por Shigella, Escherichia coli e Salmonella. Klebsiella pneumoniae é causa freqüente de doença respiratória, e Yersinia pseudotuberculosis está associada à enterocolites e peritonites. As fontes mais comuns de contaminação por esse grupo de bactérias, especialmente coliformes que incluem os gêneros Escherichia, Klebsiella, Enterobacter e Citrobacter, são fezes (de origem humana e animal), funcionários, água e containers (OMORE et al., 2001).

Tem sido mais evidente que cepas patogênicas de E. coli, como O157:H7, em níveis significantes estão presentes em fazendas leiteiras (ZHAO et al., 1995; FAITH et al., 1996; BYRNE et al., 2003). Em estudo ocorrido nos Estados Unidos, foi mostrado que, em $38,5 \%$ das operações empregadas no processo de obtenção de leite, ocorre a presença de E. coli O157 (USDA, 2003). Assim, leite com elevada concentração de coliformes termotolerantes apresenta grandes chances de estar contaminado com cepas de E. coli patogênicas.

Microrganismos do gênero Burkholderia, os quais possuem como habitats o solo, água e superfície de plantas ou raízes, foram isolados de três das 16 propriedades investigadas. De acordo com Isles (1984), B. cepacia tem sido extensivamente reconhecida como um patógeno humano ocasional, primariamente associado com infecção hospitalar entre pacientes hospitalizados com doenças debilitantes. Pacientes com doença granulomatosa crônica, uma disfunção das células brancas do sangue, são particularmente suscetíveis à infecção. No início da década de 1980, houve um aumento de identificação de B. cepacia em culturas de material proveniente do trato respiratório de pessoas com fibrose cística, a disfunção hereditária mais comum em caucasianos. De fato, em alguns centros de tratamento de fibrose cística, a B. cepacia foi encontrada infectando uma significante quantidade de pacientes e associada com o aumento das proporções de morbidade e mortalidade.

Estudos clínicos mostraram que embora alguns pacientes com fibrose cística permaneçam colonizados com B. cepacia por prolongados períodos de tempo, outros sucumbem a uma rápida e progressiva pneumonia necrosante e septicemia, referida como síndrome cepacia (LI PUMA, 2007).

\subsection{Identificação das espécies isoladas de Staphylococcus}

Das 16 propriedades analisadas, foi possível identificar Staphylococcus de apenas 10, devido ao fato de alguns isolados não terem sido recuperados após sua estocagem em ágar Simples Fosfatado.

Dentre as propriedades investigadas, as que apresentaram maior diversidade de espécies foram as CCMP e SDN. Nas duas propriedades, foram encontrados $S$. aureus, porém na propriedade CCMP, além de $S$. aureus, foi também identificado S. hyicus, sendo as duas espécies altamente patogênicas e consideradas grande problema em saúde pública. Staphylococcus aureus é um dos principais agentes etiológicos causadores de mastite clínica e subclínica. A mastite é definida como uma reação inflamatória da glândula mamária e, de acordo com a causa ou principal causa da inflamação, pode ser classificada como infecciosa, traumática ou tóxica (IDF, 1987). A mastite pode se manifestar na forma clínica ou subclínica (BRAMLEY et al., 1996). Na forma subclínica, ao contrário da forma clínica, não ocorrem mudanças visíveis na aparência do leite ou do úbere, embora ocorram alterações na composição do leite e deste possam ser isolados microrganismos patogênicos (BRAMLEY et al., 1996). A mastite subclínica tem grande impacto na produtividade dos rebanhos leiteiros porque sua prevalência é maior que a da forma clínica (PHILPOT; NICKERSON, 1991). A presença de $S$. aureus indica a manipulação inadequada do produto e más condições higiênico-sanitárias, sendo o homem de grande importância como agente transmissor.

Aproximadamente $20 \%$ dos indivíduos são colonizados por um tipo de cepa de $S$. aureus (portadores persistentes), enquanto $\pm 60 \%$ da população abriga $S$. aureus com freqüência variada 
Tebaldi et al.

Tabela 2. Microrganismos Gram-negativos oxidase negativa e positiva, identificados respectivamente pelos sistemas Bactray ${ }^{\circledR}$ I , II e III.

\begin{tabular}{|c|c|c|c|c|c|}
\hline Isolado & Espécie & $\mathrm{N}^{o}$ de isolados & Oxidase & Atividade lipolítica (\%) & Atividade proteolítica (\%) \\
\hline CXM & Enterobacter cloacae & 3 & Negativo & 66,66 & 33,33 \\
\hline \multirow[t]{3}{*}{$\mathrm{AM}$} & Escherichia coli & 1 & Negativo & 0,00 & 0,00 \\
\hline & Klebsiella pneumoniae & 3 & Negativo & 100,00 & 66,66 \\
\hline & Yersinia enterocolitica & 1 & Negativo & 0,00 & 100,00 \\
\hline MP & Klebsiella ornithinolytica & 1 & Negativo & 100,00 & 0,00 \\
\hline \multirow[t]{3}{*}{ SB } & Enterobacter cloacae & 6 & Negativo & 83,33 & 50,00 \\
\hline & Klebsiella pneumoniae & 2 & Negativo & 100,00 & 100,00 \\
\hline & Escherichia coli & 1 & Negativo & 0,00 & 0,00 \\
\hline \multirow[t]{2}{*}{ PLT } & Klebsiella pneumoniae & 4 & Negativo & 50,00 & 75,00 \\
\hline & Enterobacter aerogenes & 1 & Negativo & 0,00 & 0,00 \\
\hline FER & Yersinia pseudotuberculosis & 1 & Negativo & 0,00 & 100,00 \\
\hline BV & Klebsiella pneumoniae & 1 & Negativo & 0,00 & 100,00 \\
\hline EST & Escherichia coli & 6 & Negativo & 0,00 & 0,00 \\
\hline $\mathrm{AV}$ & Enterobacter cloacae & 1 & Negativo & 0,00 & 100,00 \\
\hline \multirow[t]{4}{*}{$\mathrm{CV}$} & Escherichia coli & 4 & Negativo & 0,00 & 0,00 \\
\hline & Klebsiella ozaenae & 1 & Negativo & 0,00 & 0,00 \\
\hline & Enterobacter cloacae & 1 & Negativo & 0,00 & 0,00 \\
\hline & Klebsiella pneumoniae & 1 & Negativo & 0,00 & 100,00 \\
\hline \multirow[t]{2}{*}{ CCMP } & Escherichia coli & 1 & Negativo & 0,00 & 0,00 \\
\hline & Klebsiella ozaenae & 1 & Negativo & 0,00 & 0,00 \\
\hline MP & Alcaligenes faecalis & 2 & Positivo & 100,00 & 100,00 \\
\hline \multirow[t]{2}{*}{ BV } & Pseudomonas pseudoalcaligenes & 2 & Positivo & 100,00 & 100,00 \\
\hline & Alcaligenes denitrificans & 4 & Positivo & 100,00 & 100,00 \\
\hline \multirow[t]{2}{*}{$\mathrm{AV}$} & Burkholderia cepacia & 1 & Positivo & 100,00 & 100,00 \\
\hline & Alcaligenes denitrificans & 1 & Positivo & 100,00 & 100,00 \\
\hline \multirow[t]{3}{*}{$\mathrm{CV}$} & Burkholderia cepacia & 1 & Positivo & 100,00 & 100,00 \\
\hline & Alcaligenes faecalis & 2 & Positivo & 100,00 & 100,00 \\
\hline & Alcaligenes denitrificans & 1 & Positivo & 100,00 & 100,00 \\
\hline
\end{tabular}

(portadores intermitentes) e, finalmente $20 \%$ dos indivíduos nunca albergam S. aureus (não-portadores) (KLUYTMANS et al., 1997).

A bactéria permanece sobre a pele, particularmente devido ao alto teor de sal e suor, onde sua eliminação pode ser transitória (HOBBS; ROBERTS, 1999).

Ainda que inconscientemente, os manipuladores são os principais carreadores da bactéria, uma vez que nessas pequenas propriedades investigadas não existem programas de Boas Práticas de Fabricação, disseminando, dessa forma, grande carga microbiana ao leite.
Os representantes do gênero Staphylococcus isolados e identificados nas propriedades investigadas, bem como suas atividades proteolítica e lipolítica podem ser visualizados na Tabela 3.

\subsection{Enterococcus}

Dentre as dezesseis propriedades avaliadas, oito delas indicaram a presença de Enterococcus. Os resultados obtidos na identificação encontram-se expressos na Tabela 4. Foram encontradas três espécies desse gênero predominando dentre as propriedades investigadas, sendo elas representadas por 
Enterococcus durans, Enterococcus faecium e Enterococcus faecalis, todas elas pertencentes ao grupo D de Lancefield, evidenciando assim sua natureza de origem fecal.

Enterococcus é comumente encontrado na microbiota do leite cru. Na Dinamarca, esse microrganismo, encontrado na ordem de $5 \times 10^{3}$ UFC. $\mathrm{mL}^{-1}$, foi isolado em $19 \%$ das amostras de leite cru mantido em tanques de refrigeração (HOLM et al., 2004). Lafarge et al. (2004), utilizando técnicas moleculares, também identificaram espécies de Enterococcus em leite cru antes da refrigeração e após 48 horas sob refrigeração a $4,4{ }^{\circ} \mathrm{C}$.

\subsection{Avaliação de proteólise e lipólise}

As proteases estão associadas com o amargor no leite e gelatinização de leite UHT. A maioria das proteases é capaz de degradar $\kappa^{-}, \alpha_{\text {s1 }}$ e $\beta$ caseínas, e são notáveis pela sua estabilidade térmica (COUSIN, 1981; Mc PHEE; GRIFFITHS, 2002).

Tabela 3. Staphylococcus identificados nas amostras de leite e suas características lipolíticas e proteolíticas.

\begin{tabular}{|c|c|c|c|c|}
\hline Isolado & Espécie & $\begin{array}{c}\text { No de } \\
\text { isolados }\end{array}$ & $\begin{array}{c}\text { Lipólise } \\
(\%)\end{array}$ & $\begin{array}{c}\text { Proteólise } \\
(\%)\end{array}$ \\
\hline \multirow[t]{2}{*}{ PLT } & Staphylococcus sp. & 1 & 100 & 100 \\
\hline & Staphylococcus caseolyticus & 1 & 100 & 100 \\
\hline $\mathrm{CC}$ & Staphylococcus sp. & 3 & 100 & 100 \\
\hline FER & Staphylococcus sp. & 1 & 100 & 100 \\
\hline BV & Staphylococcus sp. & 2 & 100 & 100 \\
\hline \multirow[t]{2}{*}{ EST } & Staphylococcus sp. & 1 & 100 & 100 \\
\hline & Staphylococcus aureus & 1 & 100 & 100 \\
\hline FLC & Staphylococcus sp. & 1 & 100 & 100 \\
\hline \multirow[t]{3}{*}{ AV } & Staphylococcus aureus & 2 & 100 & 100 \\
\hline & Staphylococcus sp. & 1 & 100 & 0 \\
\hline & Staphylococcus caseolyticus & 1 & 0 & 100 \\
\hline \multirow[t]{2}{*}{$\mathrm{CV}$} & Staphylococcus sp. & 2 & 100 & 50 \\
\hline & Staphylococcus aureus & 1 & 100 & 100 \\
\hline \multirow[t]{4}{*}{ CCMP } & Staphylococcus sp. & 1 & 0 & 100 \\
\hline & Staphylococcus aureus & 2 & 100 & 100 \\
\hline & Staphylococcus hyicus & 1 & 100 & 100 \\
\hline & Staphylococcus chromogenes & 1 & 100 & 100 \\
\hline \multirow[t]{4}{*}{ SDN } & Staphylococcus sp. & 4 & 100 & 100 \\
\hline & Staphylococcus carnosus & 1 & 100 & 100 \\
\hline & Staphylococcus aureus & 2 & 100 & 100 \\
\hline & Staphylococcus caseolyticus & 1 & 100 & 100 \\
\hline
\end{tabular}

A pasteurização reduz a atividade de fosfolipase, mas não a elimina no leite desnatado (KOKA; WEIMER, 2001). A maioria das lipases preserva sua atividade após a pasteurização e até mesmo após tratamento UHT (DEETH, 2002).

Após crescimento dos isolados em ágar Tributirina, as colônias foram avaliadas quanto à formação de halos que indicavam a atividade de lipases (lipólise). Dos 70 isolados da família Enterobacteriaceae, apenas 18 isolados apresentaramse positivos, ou seja, 25,71\%. Já os isolados Gram-negativos, oxidase positiva em sua totalidade, apresentaram-se positivos, sendo 20 os representantes.

As colônias crescidas em Milk Agar suplementado com leite em pó a $10 \%(\mathrm{v} / \mathrm{v})$ foram avaliadas quanto à atividade de protease (proteólise). Apenas 34,28\% dos 70 isolados de Enterobacteriaceae apresentaram atividade proteolítica, enquanto $100 \%$ dos isolados Gram-negativos oxidase positiva apresentaram atividade proteolítica.

Em face de tais resultados, pode-se inferir que as bactérias Gram-negativas oxidase positiva, como as dos gêneros Alcaligenes, Pseudomonas e Burkholderia, são potencialmente lipolíticas e proteolíticas, exigindo assim um maior controle higiênico sanitário para que não haja contaminação do leite com essa microbiota para garantir a qualidade do produto.

Conforme dados da Tabela 3, exceto dois isolados do gênero Staphylococcus não apresentaram atividades lipolítica e proteolítica tendo os demais apresentado forte atividade enzimática. Essa atividade enzimática permite grande multiplicação dos representantes do gênero, podendo o leite ser considerado um habitat excelente e um perigo potencial para a saúde do consumidor, caso este faça a ingestão do produto sem tratamento térmico adequado.

De acordo com os resultados expressos na Figura 1, é possível observar que em todos os grupos de microrganismos isolados notaram-se atividades de lipase e protease, porém em menor escala nos representantes Enterobacteriaceae e em maior escala nos microrganismos Gram-negativos oxidase positivos, os quais, em sua maioria, pertencentes aos gêneros Pseudomonas, Alcaligenes e Burkholderia. Esses últimos microrganismos, geralmente psicrotróficos, muitas vezes fazem parte da biota do leite cru (JAY, 2005). Embora em alguns grupos essa atividade tenha sido menor, como no caso de Enterobacteriaceae, é importante salientar que medidas preventivas precisam ser adotadas para

Tabela 4. Enterococcus spp. identificados nas amostras de leite e características lipolíticas e proteolíticas, bem como os grupos antigênicos.

\begin{tabular}{|c|c|c|c|c|c|}
\hline Isolado & Espécie & $\mathrm{N}^{\circ}$ de isolados & Lipólise (\%) & Proteólise (\%) & Grupo sorológico \\
\hline CCMP & Enterococcus durans & 3 & 0,00 & 100 & $\mathrm{D}$ \\
\hline SAP & Enterococcus faecalis & 5 & 100,00 & 100 & $\mathrm{D}$ \\
\hline \multirow[t]{2}{*}{ EST } & Enterococcus faecalis & 3 & 33,33 & 100 & $\mathrm{D}$ \\
\hline & Enterococcus faecium & 2 & 0,00 & 50 & $\mathrm{D}$ \\
\hline FLC & Enterococcus faecium & 1 & 100,00 & 100 & $\mathrm{D}$ \\
\hline EV & Enterococcus faecalis & 4 & 75,00 & 75 & $\mathrm{D}$ \\
\hline BV & Enterococcus faecalis & 1 & 0,00 & 100 & $\mathrm{D}$ \\
\hline
\end{tabular}




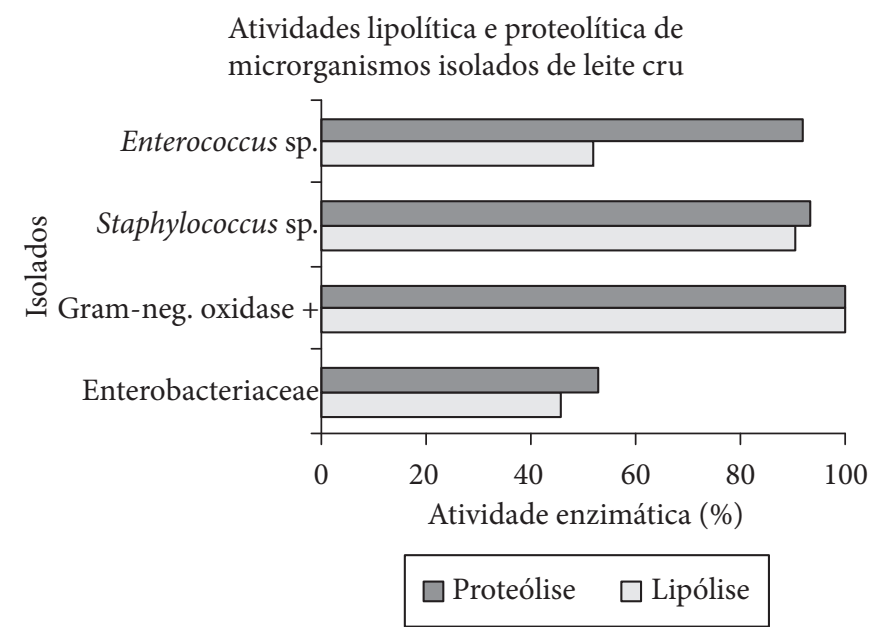

Figura 1. Percentagem de atividades lipolítica e proteolítica dos microrganismos isolados de leite.

que se possa erradicar ou inibir o crescimento deles, evitando assim a deterioração do leite.

\section{Conclusões}

Elevadas concentrações de microrganismos indicadores de qualidade foram encontradas no leite refrigerado, os quais são de grande interesse do ponto de vista de saúde pública, representando perigo potencial para aqueles indivíduos que ainda ingerem leite cru. Embora se saiba que grande parte das deteriorações enzimáticas que ocorrem no leite sejam predominantemente provocadas por microrganismos psicrotróficos, foi possível constatar sua produção por microrganismos da microbiota mesofílica em todos os grupos testados, necessitando ações direcionadas para a solução de tal problema e visando a melhora da qualidade do produto.

\section{Agradecimentos}

À CAPES e ao CNPq pelo apoio financeiro.

\section{Referências bibliográficas}

ALTEKRUSE, S. F. et al. Cheese-associated outbreaks of human illness in the United States, 1973 to 1992: Sanitary manufacturing practices protect consumers. Journal of Food Protection, v. 61, n. 10, p. 1405-1407, 1998.

BADARÓ, A. C. L.; ARAÚJO, T. F.; CARVAlhO, A. F. Análise da contaminação microbiológica, mesófilos proteolíticos e lactofermentadores do leite cru comercializado no município de Ipatinga. Revista do Laticínio Cândido Tostes, v. 62, n. 357, p. 293-299, 2007.

BRAMLEY, A. J. et al. Current concepts of bovine mastitis. In: NATIONAL MASTITIS COUNCIL, 37, 1996, Madison. Proceedings... Madison: NMC, 1996. p. 1-3.

BRASIL. Ministéro da Agricultura, Pecuária e Abastecimento. Instrução Normativa $n^{\circ} 51$, de 18 de setembro de 2002. Diário Oficial da Repúplica Federativa do Brasil, 20 set. 2002. Seção 1, p. 13-22.

BYRNE, C. M. et al. Characterization of Escherichia coli O157:H7 from downer and healthy dairy cattle in the upper Midwest region of the
United States. Applied Environmental Microbiology, v. 69, n. 8, p. $4683-4688,2003$.

BOOR, K. J. et al. Microbiological and Chemical Quality of Raw Milk in New York State. Journal Dairy Science, v. 81, n. 6, p. 1743-1748, 1998.

COUSIN, M. A. Proteolytic activity of psychrotrophic microorganisms on milk and dairy products. In: ROBERTS, T. A.; HOBBS, G.; CHRISTIAN, J. H. B.; SKOVGAARD, N. (Eds.). Psychrotrophic Microorganisms in Spoilage and Pathogenicity. New York: Academic Press, 1981. p. 63-72.

DEETH, H. C. Lipolysis. In: ROGINSKY, H.; FUQUAY, J. W.; FOX, P. F. (Eds.). Encyclopedia of Dairy Sciences. New York: Academic Press, 2002. v. 1, p. 1595-1601.

DIEZ GONZALEZ, F. et al. Grain feeding and the dissemination of acid-resistant Escherichia coli from cattle. Science, v. 281, n. 5383, p. 1666-1668, 1998.

FAITH, N. G. et al. Prevalence and clonal nature of Escherichia coli O157:H7 on dairy farms in Wisconsin. Applied Environmental Microbiology, v. 62, n. 5, p. 1519-1525, 1996.

FORSYTHE, S. J. Microbiologia da segurança alimentar. Porto Alegre: Artmed, 2002.

FRANCO, B. D. G. M.; LANDGRAF, M. Microbiologia dos alimentos. São Paulo: Atheneu, 2003.

HAYES, M. C. et al. Identification and Characterization of Elevated Microbial Counts in Bulk Tank Raw Milk. Journal Dairy Science, v. 84 , n. 1, p. 292-298, 2001.

HOBBS, B. C.; ROBERTS, D. Toxinfecções e controle higiênicosanitário de alimentos. Tradução de Silvia Panetta Nascimento e Marcelo Arruda Nascimento. São Paulo: Varela, 1999. (Título original: Food poisoning and food hygiene).

HOLT, J. G. et al. Bergey's manual of determinative bacteriology. 9 ed. Baltimore: Willians \& Wilkins, 1994. 787 p.

IDF. Bovine mastitis: Definition and guidelines for diagnosis. IDF Bulletin 211/1987. Brussels, Belgium: International Dairy Federation, 1987.

INTERNATIONAL COMMISSION ON MICROBIOLOGICAL SPECIFICATION FOR FOODS. Microorganismos de los alimentos: su significado y metodos de emuneración. 2 ed. Zaragoza: Acribia, 2000. 367 p.

ISLES, A. Pseudomonas cepacia infection in cystic fibrosis: an emerging problem. The Journal of Pediatrics, v. 104, n. 2, p. 206-210, 1984.

JAY, J. M. Microbiologia de Alimentos. 6 ed. Porto Alegre: Ed. Artmed, 2005.

JAYARAO, B. M. et al. Guidelines for Monitoring Bulk Tank Milk Somatic Cell and Bacterial Counts. Journal Dairy Science, v. 87, n. 10, p. 3561-3573, 2004.

KLUYTMANS, J.; BELKUM, A. V. H. Nasal carriage of Staphylococcus aureus: epidemiology, underlying mechanisms and associated risks. Clinical Microbiology Reviews, v. 10, n. 3, p. 505-520, 1997.

KOKA, R.; WEIMER, B. C. Influence of growth conditions on heatstable phospholipase activity in Pseudomonas. Journal of Dairy Research, v. 68, n. 01, p. 109-116, 2001.

LAFARGE, V. et al. Raw Cow Milk Bacterial Population Shifts Attributable to Refrigeration. Applied Environmental Microbiology, v. 70, n. 9, p. 5644-5650, 2004.

LAVEN, R. A.; ASHMORE, A.; STEWART, C. S. Escherichia coli in the rumen and colon of slaughter cattle, with particular reference to $E$. coli O157. Veterinary Journal, v. 165, n. 1, p. 78-83, 2003. 
LI PUMA, J. J. Update on Burkholderia Nomenclature and Resistance. Clinical Microbiology Newsletter, v. 29, n. 9, p. 65-69, 2007.

McPHEE, J. D.; GRIFFITHS, M. W. Psychrotrophic bacteria, Pseudomonas spp. In: ROGINSKY, H.; FUQUAY, J. W.; FOX, P. F. (Eds.). Encyclopedia of Dairy Sciences. New York: Academic Press, 2002. v. 4, p. 2340-2351.

OMORE, A. et al. Assessing and managing milk-born health risks for the benefit of consumers in Kenya. Nairobi, Kenya: Smallholder Dairy (R\&D) Project (SDP), 2001. 46 p.

PHILPOT, W. N.; NICKERSON, S. C. Mastitis: counter attack. Naperville: Babson Bros, 1991. 150 p.

RYSER, E. T. Public health concerns. In: MARTH, E. H.; STEELE, J. L. (Eds.). Applied Dairy Microbiology. New York: Marcel Dekker, Inc., 1998. p. 263-403.
TATINI, S. R. Influence of food environments of growth of Staphylococcus aureus and production of various enterotoxins. Journal Milk Food Technology, v. 36, n. 2, p. 474, 1973.

USDA. Salmonella and Campylobacter on U.S. Dairy Operations. Fort Collins: USDA; APHIS; VS; CEAH, 2003b.

VALEEVA, J. G. et al. Improving Food Safety Within the Dairy Chain: An Application of Conjoint Analysis. Journal Dairy Science, v. 88, n. 4, p. 1601-1612, 2005.

VAN KESSEL, J. S. et al. Effects of ruminal and postruminal infusion of starch hydrolysate or glucose on the microbial ecology of the gastrointestinal tract in growing steers. Journal of Animal Science, v. 80, n. 11, p. $3027-3034,2002$.

ZHAO, T. et al. Prevalence of enterohemorrhagic Escherichia coli O157:H7 in a survey of dairy herds. Applied Environmental Microbiology, v. 61, n. 4, p. 1290-1293, 1995. 